\title{
Cloning, tissue and ontogenetic expression of the taurine transporter in the flatfish Senegalese sole (Solea senegalensis)
}

\author{
Wilson Pinto • Ivar Rønnestad • Ann-Elise Olderbakk Jordal • \\ Ana S. Gomes · Maria Teresa Dinis · Cláudia Aragão
}

Received: 23 September 2010/ Accepted: 20 December 2010/Published online: 6 January 2011

(C) The Author(s) 2011. This article is published with open access at Springerlink.com

\begin{abstract}
Flatfish species seem to require dietary taurine for normal growth and development. Although dietary taurine supplementation has been recommended for flatfish, little is known about the mechanisms of taurine absorption in the digestive tract of flatfish throughout ontogeny. This study described the cloning and ontogenetic expression of the taurine transporter (TauT) in the flatfish Senegalese sole (Solea senegalensis). Results showed a high similarity between TauT in Senegalese sole and other vertebrates, but a change in TauT amino acid sequences indicates that taurine transport may differ between mammals and fish, reptiles or birds. Moreover, results showed that Senegalese sole metamorphosis is an important developmental trigger to promote taurine transport in larvae, especially in muscle tissues, which may be important for larval growth. Results also indicated that the capacity to uptake dietary taurine in the digestive tract is already established in larvae at the onset of metamorphosis. In Senegalese sole juveniles, TauT expression was highest in brain, heart and eye. These are organs where taurine is usually found in high concentrations and is believed to play important biological roles. In the digestive tract of juveniles, TauT was more expressed in stomach and hindgut, indicating that dietary taurine is quickly absorbed when
\end{abstract}

Electronic supplementary material The online version of this article (doi:10.1007/s00726-010-0826-6) contains supplementary material, which is available to authorized users.

W. Pinto $(\varangle) \cdot$ M. T. Dinis · C. Aragão CIMAR/CCMAR, Universidade do Algarve, Campus de Gambelas, 8005-139 Faro, Portugal

e-mail:wpinto@ualg.pt

I. Rønnestad · A.-E. O. Jordal · A. S. Gomes Department of Biology, University of Bergen, $\mathrm{Pb} 7803,5020$ Bergen, Norway digestion begins and taurine endogenously used for bile salt conjugation may be recycled at the posterior end of the digestive tract. Therefore, these results suggest an enterohepatic recycling pathway for taurine in Senegalese sole, a process that may be important for maintenance of the taurine body levels in flatfish species.

Keywords Taurine transporter - TauT - SLC6A6 ·

Senegalese sole $\cdot$ Flatfish · Ontogeny

\section{Introduction}

Taurine is an amino sulphonic acid that is among the most abundant low molecular weight organic constituents of animal tissues. For instance, taurine alone accounts for approximately $0.1 \%$ of total body weight in humans. Although often considered an amino acid (AA), taurine lacks a carboxyl group and is not incorporated into proteins. Instead, taurine is freely distributed throughout cytosol, and is particularly accumulated in excitable tissues. Taurine plays a vital role in several important biological functions such as bile salt conjugation, osmoregulation, membrane stabilisation, modulation of neurotransmitters, antioxidation, and early development of visual, neural and muscular systems (Huxtable 1992).

Due to its abundance in animal tissues, taurine is highly available in carnivorous and omnivorous diets. Several animals may temporarily or permanently depend on a dietary source of taurine, due to limited endogenous rate of taurine biosynthesis caused by an inherent deficiency on the enzyme cysteine sulfinate decarboxylase. For instance, cats are completely unable to biosynthesise taurine and offspring of female cats that are fed taurine-deficient diets may not survive or may develop neurological defects and retinal 
degeneration (Hayes et al. 1975; Sturman 1988). In fish, the ability to biosynthesise taurine varies inter-specifically and throughout ontogenesis (Goto et al. 2001, 2003; Yokoyama et al. 2001; Kim et al. 2003, 2008), indicating that taurine may be essential for various fish species during some developmental stages. This seems to be the case for Japanese flounder (Paralichthys olivaceus), which has been shown to have a low capacity for taurine biosynthesis, requiring dietary taurine for normal growth, development and feeding behaviour (Kim et al. 2005, 2008). Based on this, dietary taurine supplementation is recommended on a general basis for flatfish during ontogeny (Takeuchi 2001).

Dietary taurine deficiencies may be particularly critical for flatfish during the larval stage. On one hand, taurine levels remain stable during the yolk-sac and mouth opening stages of flatfish development, suggesting that taurine is incorporated into the free AA pool of the egg before spawning (Rønnestad and Fyhn 1993; Rønnestad et al. 1993). Like in the mammalian embryo, these findings suggest that taurine may have a significant physiological importance for the development of fish embryo (Sturman 1993). Furthermore, the prey of flatfish larvae in the natural environment (e.g. copepods) contain high taurine levels (Conceição et al. 1997; van der Meeren et al. 2008), and high taurine levels in live food were suggested to result in higher growth rates of turbot (Scophthalmus maximus) larvae (Conceição et al. 1997). Nevertheless, although dietary taurine supplementation is likely to be beneficial for flatfish larvae, there is no information available on the mechanisms involved in taurine absorption in the digestive tract and the bioavailability of dietary taurine in the early developmental stages.

The research on intestinal taurine transport in vertebrates mainly targets the high-affinity, low-capacity sodium/ chloride-dependent taurine transporter (TauT; SLC6A6) (ÓFlaherty et al. 1997). This transporter functions as an active transport system that carries taurine against a concentration gradient, driven by transmembrane sodium and chloride gradients and membrane potentials. TauT has been cloned and characterised in a range of species and tissues, including Madin-Darby canine kidney cells (Uchida et al. 1992), porcine renal proximal tubule cells (Jones et al. 1995), mouse (Liu et al. 1992) and human (Jhiang et al. 1993; Ramamoorthy et al. 1994). In fish, only a few studies have aimed to characterise TauT (Takeuchi et al. 2000; Zarate and Bradley 2007; Kozlowski et al. 2008; Chow et al. 2009), and to our knowledge no work has analysed TauT expression in flatfish species or during fish larval stages. In fact, up to now few works have been done on the molecular characterisation of transporters in teleosts in general (e.g. Verri et al. 2003) and in larvae (Amberg et al. 2008). In mammals, several AA transporters appear at different times during ontogenesis (Buddington and Diamond 1989). Although the ontogeny of fish larvae is not comparable to foetal mammals, it remains to be explored if this also holds true for teleosts. It has been shown that fish larvae do not have a fully developed digestive system at the onset of exogenous feeding and the digestive/absorption capacities increase along with development (Conceição et al. 2007; Rønnestad et al. 2007). Therefore, since flatfish may require dietary taurine supplementation during the early developmental stages, it is important to determine the functionality of TauT during ontogenesis.

This work aimed to characterise TauT expression during the ontogeny of Senegalese sole (Solea senegalensis), a flatfish species with increasing importance for the SouthEastern European aquaculture (Imsland et al. 2003; Conceição et al. 2007) and that seems to require dietary taurine supplementation during the early life stages (Pinto et al. 2010). For this purpose, TauT was cloned from Senegalese sole cDNA and its expression was determined by real time quantitative PCR (qPCR) from first feeding larvae until juvenile stages of development.

\section{Materials and methods}

\section{Fish rearing}

Senegalese sole (S. senegalensis) larvae were reared at UAlg (Faro, Portugal) according to standard procedures until 30 days after hatching (DAH) (Dinis et al. 1999). Larvae were initially reared in $100 \mathrm{~L}$ conical cylindrical sandcoloured tanks at a density of 80 larvae $\mathrm{L}^{-1}$. At $16 \mathrm{DAH}$, benthonic Senegalese sole were transferred to $21 \mathrm{~L}$ sandcoloured fibreglass raceways $\left(0.21 \mathrm{~m}^{2} ; 10 \mathrm{~cm}\right.$ water depth; initial larval density of 3,000 individuals $\mathrm{m}^{-2}$ ). Light/dark cycles of 12:12 $\mathrm{h}$ were used throughout the experiment. Water temperature $\left(21.0 \pm 1.5^{\circ} \mathrm{C}\right.$; mean $\left.\pm \mathrm{SD}\right)$, oxygen saturation level $(96.1 \pm 4.6 \%)$ and salinity (33.8 \pm $2.6 \mathrm{~g} \mathrm{~L}^{-1}$ ) were measured on a daily basis. The Senegalese sole larvae were fed rotifers and Artemia enriched with commercial products according to standard rearing procedures (Dinis et al. 1999).

Juvenile Senegalese sole were obtained from a different batch of larvae reared at CCMAR (Faro, Portugal) facilities in a flat-bottom sand-coloured fibreglass tank $(2.40 \mathrm{~m}$ length; $1 \mathrm{~m}$ width; $30 \mathrm{~cm}$ depth) at a density of $8 \mathrm{~kg} \mathrm{~m}^{-2}$. Water supply was provided by a partial-recirculated water system (temperature $21 \pm 1^{\circ} \mathrm{C}$; salinity $36 \mathrm{~g} \mathrm{~L}^{-1}$ ). Fish were fed to satiety with a commercial diet (Dourasoja Balance, Sorgal, S.A.) and fasted for $24 \mathrm{~h}$ before sampling.

Fish sampling

Senegalese sole larvae were sampled for total length (TL), dry weight (DW) and metamorphosis pattern analysis at 
Table 1 Primer sequences for amplification and expression analysis of taurine transporter in S. senegalensis

\begin{tabular}{llll}
\hline & Primer sequence $5^{\prime} \rightarrow 3^{\prime}$ & Amplification region (bp) & Amplicon length (bp) \\
\hline TauT cloning & ATGGCACAGAAAGAGAAACTCCA (Fw) & $1-23$ & 750 \\
& TTGCTGTTATGTAGACCACTTTCCC (Rev) & $727-751$ & 1,222 \\
TauT cloning & TCGCTGTGTGGGTCATCTGC (Fw) & $674-693$ & $1,875-1,895$ \\
TauT qPCR & CCTCTCACAGAGAGCGTTCAC (Rev) & $1,123-1,143$ & 120 \\
& CCGAAAGCTGTGTCCATGATG (Fw) & $1,220-1,243$ & 142 \\
eEF1al qPCR & CAATAGAGGTGATCTGTCCTTCCA (Rev) & - & \\
& GATTGACCGTCGTTCTGGCAAGAAGC (Fw) & & \\
\hline
\end{tabular}

TauT taurine transporter, eEFlal elongation factor 1 alpha isoform $1, F w$ forward primer, Rev reverse primer, $q P C R$ real time quantitative PCR

2, 6, 12, 16, 20 and $30 \mathrm{DAH}$. The metamorphosis pattern was assessed according to Fernández-Díaz et al. (2001). These authors categorised five metamorphic stages, according to the eye migration status: 0 , pre-metamorphic (symmetric larvae); 1, early metamorphic (beginning of left eye migration); 2 , middle metamorphic (left eye touching the midline of the dorsal surface); 3 , middle metamorphic (changing in the swimming plane and left eye migration within the ocular side); and 4, later metamorphic (completion of left eye migration and visibility of orbital arch).

For gene expression analysis whole larvae were collected at the same sampling points as above $(2,6,12,16$, 20 and 30 DAH). From 12 DAH onwards, additional larvae were dissected to reveal the compartmental distribution of TauT; larvae were separated into three fractions: (1) head (including heart), (2) digestive tract with liver and (3) remaining body. Samples from whole and dissected larvae were rapidly transferred to RNAlater (Ambion) and stored at $-80^{\circ} \mathrm{C}$ for later analysis.

For further analysis of the organ and tissue distribution of the taurine transporter, Senegalese sole juveniles $(94.1 \pm$ $18.1 \mathrm{~g}$ wet weight; $17.6 \pm 0.7 \mathrm{~cm}$ total length) were killed with a lethal dose of 2-phenoxiethanol (Sigma, St Louis, MO, USA). The fish were then dissected and the following samples were collected for gene expression analysis: brain, eye, gills, heart, head kidney, spleen, gallbladder, liver, stomach, midgut (divided into four equal fractions) and hindgut (divided into two equal fractions). The samples were stored in RNAlater at $-80^{\circ} \mathrm{C}$ until analysis.

Cloning and sequence analysis of Senegalese sole taurine transporter

Total RNA (RNA) was extracted from midgut of juvenile Senegalese sole using TRI Reagent (Sigma). First-strand cDNA was subsequently synthesised from RNA ( $3 \mu \mathrm{g})$ using oligo (dT) primer from SuperScript III First-Strand Synthesis system for RT-PCR kit (Invitrogen). Amplifications were performed on the resulting cDNA using primer sets designed on Primer premier 5 (Biosoft international) and based upon Common carp (Cyprinus carpio) mRNA (Genbank accession No. AB006986.1; Table 1). Amplification reactions were performed using GoTaq PCR reagents (Promega) according to the manufacturer's instructions and by the following protocol: $95^{\circ} \mathrm{C}$ for 2 min followed by 32 cycles of $95^{\circ} \mathrm{C}$ for $30 \mathrm{~s}, 55^{\circ} \mathrm{C}$ for $45 \mathrm{~s}$ and $72^{\circ} \mathrm{C}$ for $90 \mathrm{~s}$ and a final termination step of $72^{\circ} \mathrm{C}$ for $5 \mathrm{~min}$. The amplified PCR products were visualised in an agarose gel $(1 \%)$ stained with GelRed (Biotium), purified using a QIAquick Gel Extraction Kit (Qiagen) and cloned into the pCR4-TOPO vector (TOPO TA Cloning Kit, Invitrogen). Sequencing was performed at the University of Bergen Sequencing Facility (Bergen, Norway), using BigDye Terminator v3.1 chemistry in a ABI PRISM377 DNA sequencer (Applied Biosystems). Nucleotide sequences were identified using the Basic Local Alignment Search Tool (BLAST) from GenBank database.

The Senegalese sole TauT gene structure was deduced with Spidey software (http://www.ncbi.nlm.nih.gov/IEB/ Research/Ostell/Spidey) following identification of intron/ exon splices boundary consensus sequences (AG/GT). To confirm the predicted gene organisation, comparisons were performed with TauT sequence in other species using Ensembl database (http://www.ensembl.org/). Conserved domains present in protein sequence were identified using InterProScan (http://www.ebi.ac.uk/Tools/InterProScan/) and putative transmembrane domains were predicted using TMHMM 2.0, which is part of the Simple Modular Architecture Research Tool. Transmembrane protein 2D topology was created using TOPO2 software (Johns 2010).

Multiple alignment of TauT AA sequences was performed with ClustalX (version 2.0.11) according to the following parameters: Gonnet series matrix, Gap opening penalty 10, Gap extension 0.2 (Thompson et al. 1997; Larkin et al. 2007). Alignments were displayed in GeneDoc (www.psc.edu/biomed/genedoc), edited and percentages of sequence identity and similarity were calculated. 
Phylogenetic analysis was performed by Maximum Parsimony (Eck and Dayhoff 1966), using MEGA 4.0 software (Tamura et al. 2007) to build a tree with 1,000 bootstrap replicates based on vertebrate TauT AA sequences. The sequence from the Human solute carrier SLC6A13 (neurotransmitter transporter, GABA; Genbank accession No. ENSP00000339260) was used as an outgroup.

\section{Taurine transporter expression analysis}

For analysis of TauT expression, RNA was isolated from Senegalese sole tissues (see "Fish sampling" for further information on sampled tissues). RNA quality was assessed on all samples using Agilent 2100 Bioanalyzer (Agilent Technologies) and only samples with a RNA integrity number (RIN) equal or higher than 7 , on a scale of 1-10, were utilised for first-strand cDNA synthesis, since a high RNA integrity seems to be crucial for obtaining meaningful gene expression data (Fleige and Pfaffl 2006). First-strand cDNA synthesis occurred according to the procedures previously described. Senegalese sole TauT mRNA expression was analysed by qPCR using a Chromo4 Continuous Fluorescence Detector (Bio-Rad). The qPCR was performed in a volume of $25 \mu$ containing cDNA generated from $100 \mathrm{ng}$ of original mRNA template, $300 \mathrm{nM}$ of forward and reverse primers and $12.5 \mu \mathrm{l}$ of SYBR Green PCR master mix (Applied Biosystems). Primers were designed to hybridise in different exons (Table 1), thereby avoiding contamination by genomical DNA and false positive signal in qPCR (Kubista et al. 2006). Genomic DNA contamination was also monitored in every assay using a sample free of reverse transcribed cDNA (minus RT control). The amplification protocol used was: $94^{\circ} \mathrm{C}$ for $3 \mathrm{~min}$ and 40 cycles at $94^{\circ} \mathrm{C}$ for $30 \mathrm{~s}, 60^{\circ} \mathrm{C}$ for $30 \mathrm{~s}$ and $72^{\circ} \mathrm{C}$ for $30 \mathrm{~s}$. Absence of primer dimers and non-specific products was verified in every $\mathrm{qPCR}$ assay by melting curve analysis (temperature reading every $0.2^{\circ} \mathrm{C}$ from $60^{\circ} \mathrm{C}$ until $95^{\circ} \mathrm{C}$ ). qPCR analysis was conducted in triplicate reactions for all samples.

Senegalese sole elongation factor 1 alpha isoform 1 (eEF1a1; Genbank accession No. AB326302) was used as an internal reference gene for normalisation of TauT mRNA expression. Amplification of eEF1a1 was performed according to Infante et al. (2008), while cloning and sequencing occurred as previously described. Standard curves (tenfold dilution series) were generated for Senegalese sole TauT and eEF1a1 by plotting the cycle threshold $(\mathrm{Ct})$ obtained in qPCR analysis versus the logarithm of standard copy numbers $(\mathrm{CN})$ and performing a linear regression (Bustin 2000). These curves were used to estimate efficiency in every qPCR assay, showing correlation coefficients higher than 0.99 and a mean efficiency of $98.8 \pm 1.9 \%$. Senegalese sole TauT and eEF1a1 copy numbers were calculated for each sample based on the respective standard curve, using the following expression: $\mathrm{CN}=(\mathrm{Ct}-$ intercept $) \times(\text { slope })^{-1}$. TauT copy numbers

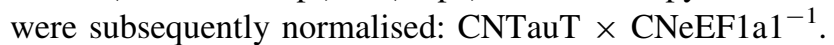

Data analysis

Results were expressed as mean \pm standard deviation (SD). Data were initially tested by Levene's test for homogeneity of variances. When homogeneity of variances was observed, detection of group mean differences was tested by one-way ANOVA followed by Tukey's multiple comparison tests. Data were analysed through KruskallWallis and Mann-Whitney $U$ non parametric tests, when mean variances were significantly different across groups. Data regarding Senegalese sole metamorphosis pattern were analysed through Chi-square tests. The significance level was $P \leq 0.05$. All results expressed as a percentage were based on arcsine transformed data (Ennos 2007).

\section{Results}

Cloning of Senegalese sole taurine transporter

The full coding cDNA sequence for Senegalese sole TauT was $1,895 \mathrm{bp}$ long, with an open reading frame of $1,878 \mathrm{bp}$ (Genbank accession No. HQ148721) encoding for a putative protein with $625 \mathrm{AA}$ and a predicted molecular weight of $70 \mathrm{kDa}$ (Fig. 1). TauT structure comparisons and hydropathy analysis predicted 14 exons and 12 putative transmembrane helices, respectively (Supplemental Figure 1). Three signature fingerprints were identified among the AA residues of Senegalese sole TauT, corresponding to the sodium/chloride-dependent neurotransmitter transporter superfamily (eight elements), neurotransmitter symporter family (two elements) and taurine transporters (four elements) (Fig. 1 and Supplemental Figure 1).

The multiple AA sequence alignment (Supplemental Figure 2) showed that TauT was very similar among Senegalese sole and the remaining vertebrates, sharing at least $76 \%$ identity with mammals and not less than $87 \%$ with other teleosts. The intracellular segment 4 (S4) was highly conserved among vertebrates, but changes in AA residues $319(\mathrm{~K})$ and $322(\mathrm{C})$ were found for Senegalese sole (Supplemental Figures 1 and 2). C322 was also found in other fish, reptiles and birds, but a serine replacement was found in this position for mammals.

Two major clades were found in the phylogenetic tree constructed with vertebrate TauT AA sequences, corresponding to a division between mammals and other vertebrates. Senegalese sole TauT was grouped with other teleost species (Supplemental Figure 3). 
Fig. 1 Nucleotide and predicted amino acid sequences for $S$. senegalensis taurine transporter (TauT). Numbers on the left refer to nucleotide (upper row) and amino acid (lower row) positions.

Nucleotide numbering starts on the initiation codon (first ATG), while asterisk indicates the stop codon (TGA). Predicted alternating exons are represented by white and grey colors. Signature for the sodium/chloride-dependent neurotransmitter transporter superfamily is provided by an eight element fingerprint (underlined from I to VIII). Signature for neurotransmitter symporter family is provided by a two element fingerprint represented by white boxes, while signature for taurine transporters is provided by a four element fingerprint (double underlined from 1 to 4 )
1 ATGGCACAGAAAGAGAAACTCCAGTGCCTGAAGGATTTCCATAAGGACACT

$\begin{array}{llllllllllllllllll}1 & M & A & Q & K & E & K & \text { L } & \mathcal{Q} & \text { C } & \text { L } & \text { K } & \text { D } & \text { F } & \text { H } & \text { K } & \text { D } & \text { T }\end{array}$

52 CTGAAACCATCTCCTGGCAAGAGCCCAGGCACTCGGCCTGAAGATGAAGCA $\begin{array}{lllllllllllllllllll}18 & L & K & P & S & P & G & K & S & P & G & T & R & P & E & D & E & A\end{array}$

103 GAGGGCAAACACCCCCAGCGGGAGAAGTGGGCCAGCAAGTTGGACTTTGTT

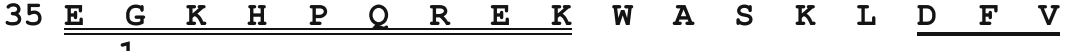

154 CTGTCTGTAGCTGGTGGCTTTGTTGGTTTAGGGAATGTGTGGCGTTTCCCG

\begin{tabular}{lllllllllllllllllll|}
52 & L & S & V & A & G & G & F & V & G & L & G & N & V & W & R & F & P \\
\hline
\end{tabular}

205 TACCTCTGCTATAAAAATGGTGGAGGTGCATTTCTCATCCCATACTTCATT

69 \begin{tabular}{|lllllllllllllllll}
$\mathrm{Y}$ & $\mathrm{L}$ & $\mathrm{C}$ & $\mathrm{Y}$ & $\mathrm{K}$ & $\mathrm{N}$ & $\mathrm{G}$ & $\mathrm{G}$ & $\mathrm{G}$ & $\mathrm{A}$ & $\mathrm{F}$ & $\mathrm{L}$ & $\mathrm{I}$ & $\mathrm{P}$ & $\mathrm{Y}$ & $\mathrm{F}$ & $\mathrm{I}$ \\
\hline
\end{tabular}

256 TTCCTGTTTGGTGGTGGTCTGCCAGTCTTCTTTCTGGAGGTCGCCCTGGGT

$\begin{array}{llllllllllllllllll}86 & \text { F } & \text { L } & \text { F } & \text { G } & \text { G } & \text { G } & \text { L } & \text { P } & \text { V } & \text { F } & \text { F } & \text { L } & \text { E } & \text { V } & \text { A } & \text { I } & \text { G }\end{array}$

307 CAGTTTACCTCCGAGGGTGGTATCACTTGCTGGGAGAAGCTCTGCCCCATC

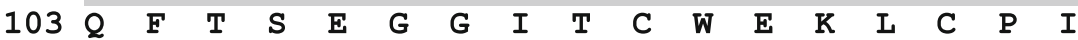

358 TTTACTGGTATTGGTTACGCCTCCATTGTGATCGTTTCCCTTTTGAATATC

$\begin{array}{llllllllllllllllll}120 & \text { F } & \text { T } & \text { G } & \text { I } & \text { G } & \text { Y } & \text { A } & \text { S } & \text { I } & \text { V } & \text { I } & \text { V } & \text { S } & \text { L } & \text { L } & \text { N } & \text { I }\end{array}$

409 TACTACATCGTCATCCTGGCCTGGGGCGTCTACTACCTGTTCCAGTGTTTT \begin{tabular}{llllllllllllllllll|}
137 & Y & Y & I & V & I & L & A & W & G & V & Y & Y & I & F & Q & C & F \\
\hline
\end{tabular}

460 CAGCCAGAGCTTCCCTGGGCCAAGTGCAATCAGCCGTGGAATACCGATCGC $\begin{array}{lllllllllllllllllll}154 & \text { Q } & \text { P } & \text { E } & \text { L } & \text { P } & \text { W } & \text { A } & \text { K } & \text { C } & \text { N } & \text { Q } & \text { P } & \text { W } & \text { N } & \text { T } & \text { D } & \text { R }\end{array}$

511 TGCATCGAGGACACCTACCGCAATAACAAAACCCTTTGGCTGGCTTCCAAC

$\begin{array}{llllllllllllllllll}171 & \mathbf{C} & \mathbf{I} & \mathbf{E} & \mathrm{D} & \mathbf{T} & \mathbf{Y} & \mathbf{R} & \mathbf{N} & \mathbf{N} & \mathrm{K} & \mathrm{T} & \mathrm{L} & \mathbf{W} & \mathrm{L} & \mathbf{A} & \mathbf{S} & \mathbf{N}\end{array}$

562 ACCTCCAACTTTACTTCCCCTGTCACCGAGTTCTGGGAACGCAATGTGCTG $\begin{array}{llllllllllllllllll}188 & \mathrm{~T} & \mathrm{~S} & \mathrm{~N} & \mathrm{~F} & \mathrm{~T} & \mathrm{~S} & \mathrm{P} & \mathrm{V} & \mathrm{T} & \mathrm{E} & \mathrm{F} & \mathrm{W} & \mathrm{E} & \mathrm{R} & \mathbf{N} & \mathrm{V} & \mathrm{L}\end{array}$

613 GGAATCAGCAATGGTATTGATGAGATAGGCCCTATTAAATGGGACCTGGCT $\begin{array}{llllllllllllllllll}205 & G & I & S & N & G & I & D & E & I & G & P & I & K & \text { W } & \text { D } & \text { I } & \text { A }\end{array}$

664 CTGTGTTTACTGCTCGTCTGGGTCATCTGCTTTTTCTGCATCTGGAAGGGA $\begin{array}{llllllllllllllllll}222 & \text { L } & \text { C } & \text { L } & \text { L } & \text { L } & \text { V } & \text { W } & \text { V } & \text { I } & \text { C } & \text { F } & \text { F } & \text { C } & \text { I } & \text { W } & \text { K } & \text { G }\end{array}$

715 GTCAGGTCCACTGGGAAAGTGGTCTACATAACAGCAACTTTCCCATTTGTA $\begin{array}{llllllllllllllllll}239 & V & R & S & T & G & K & V & V & Y & \text { I } & \text { T } & \text { A } & \text { T } & \text { F } & \text { P } & \text { F } & \text { V } \\ \end{array}$

766 ATGCTGATTGTGCTATTGATCCGCGGTGTGACTCTTCCTGGGGCAGCTGAA $\begin{array}{llllllllllllllllll}256 & \text { M } & \text { L } & \text { I } & \text { V } & \text { L } & \text { I } & \text { I } & \text { R } & \text { G } & \text { V } & \text { T } & \text { L } & \text { P } & \text { G } & \text { A } & \text { A } & \text { E }\end{array}$ 817 GGAATTAAATTTACCTTTACCCAGACCTGACCCGCCTGCAGGACCCAGAG $\begin{array}{llllllllllllllllll}273 & G & \text { I } & \text { K } & \text { F } & \text { Y } & \text { L } & \text { Y } & \text { P } & \text { D } & \text { L } & \text { T } & \text { R } & \text { L } & \text { Q } & \text { D } & \text { P } & \text { E }\end{array}$

868 GTGTGGATTGATGCTGGAACCCAGATCTTCTTCTCCTATGCCATTTGTCTG $\begin{array}{llllllllllllllllll}290 & V & \text { W } & \text { I } & \text { D } & \text { A } & G & \text { T } & \text { Q } & \text { I } & \text { F } & \text { F } & \text { S } & \text { Y } & \text { A } & \text { I } & \text { C } & \text { L }\end{array}$ 919 GGAGCCATGACATCACTGGGGAGCTACAACAAGTACAGATACAACTGCTAC $\begin{array}{llllllllllllllllll}307 & G & A & M & \text { T } & \text { S } & \text { L } & \text { G } & \text { S } & \text { Y } & \text { N } & \text { K } & \text { Y } & \text { R } & \text { Y } & \text { N } & \text { C } & \text { Y }\end{array}$ 970 AgGGACTGTTTGCTGCTGGGAGGCCTCAACAGCGGTACCAGCTTTGTGTCT \begin{tabular}{llllllllllllllllll}
324 & $R$ & $D$ & $C$ & L & L & L & G & G & L & N & S & G & T & S & F & V & S \\
\hline
\end{tabular} 
Fig. 1 continued

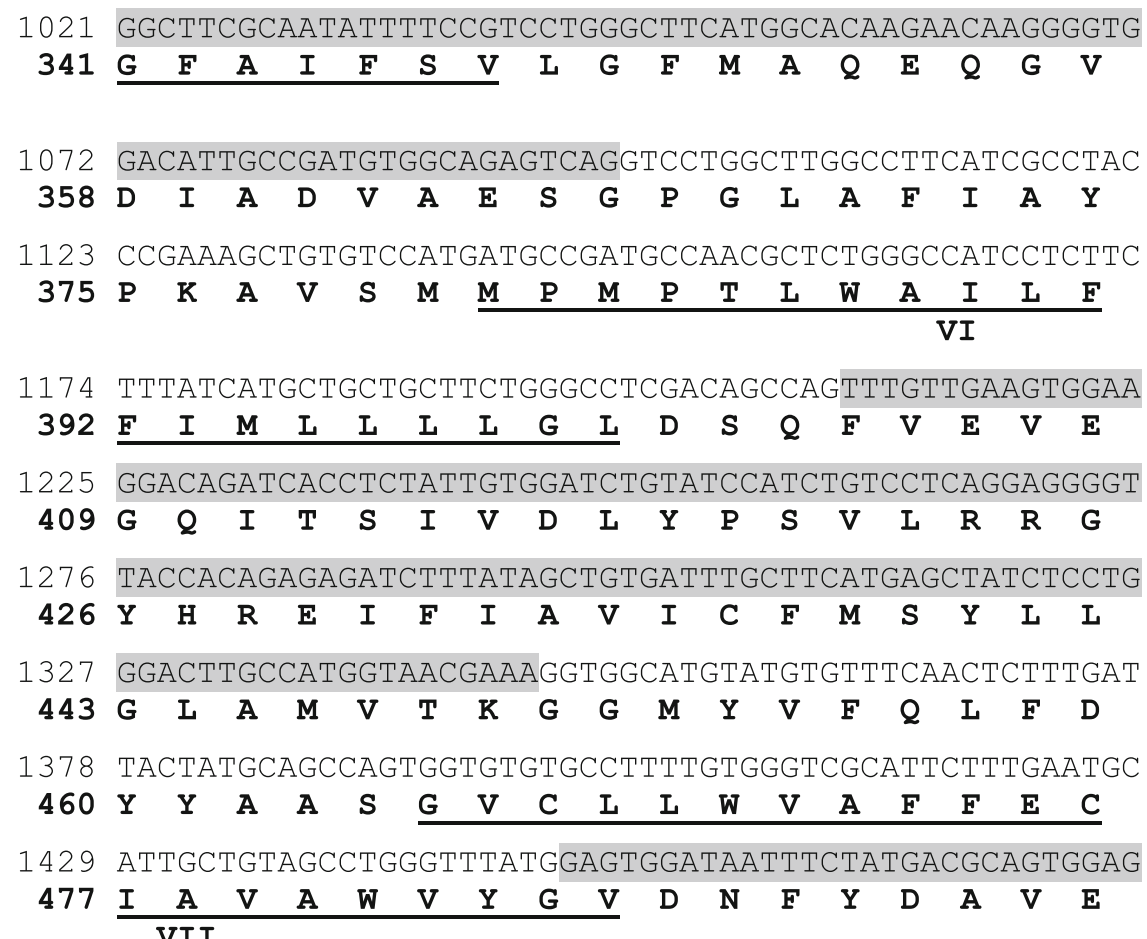

Expression of the taurine transporter during Senegalese sole ontogeny

Senegalese sole larvae grew exponentially during the experimental period, attaining approximately $5 \mathrm{mg} \mathrm{DW}$ and $13 \mathrm{~mm}$ TL by the end of the first month of development. Eye migration started at $12 \mathrm{DAH}$, with about $45 \%$ of the larvae being found in early metamorphic stage 1 and around $33 \%$ at middle metamorphic stage 2 (Fig. 2). At 20 DAH, $95 \%$ of Senegalese sole larvae had finished eye migration (later metamorphic stage 4), but this process was only concluded in all larvae at $30 \mathrm{DAH}$.

The expression of TauT in Senegalese sole larvae increased along the first month of development (Fig. 2). This increase was primarily significant from 6 to $12 \mathrm{DAH}$, while the highest expression level was found at $30 \mathrm{DAH}$. In 


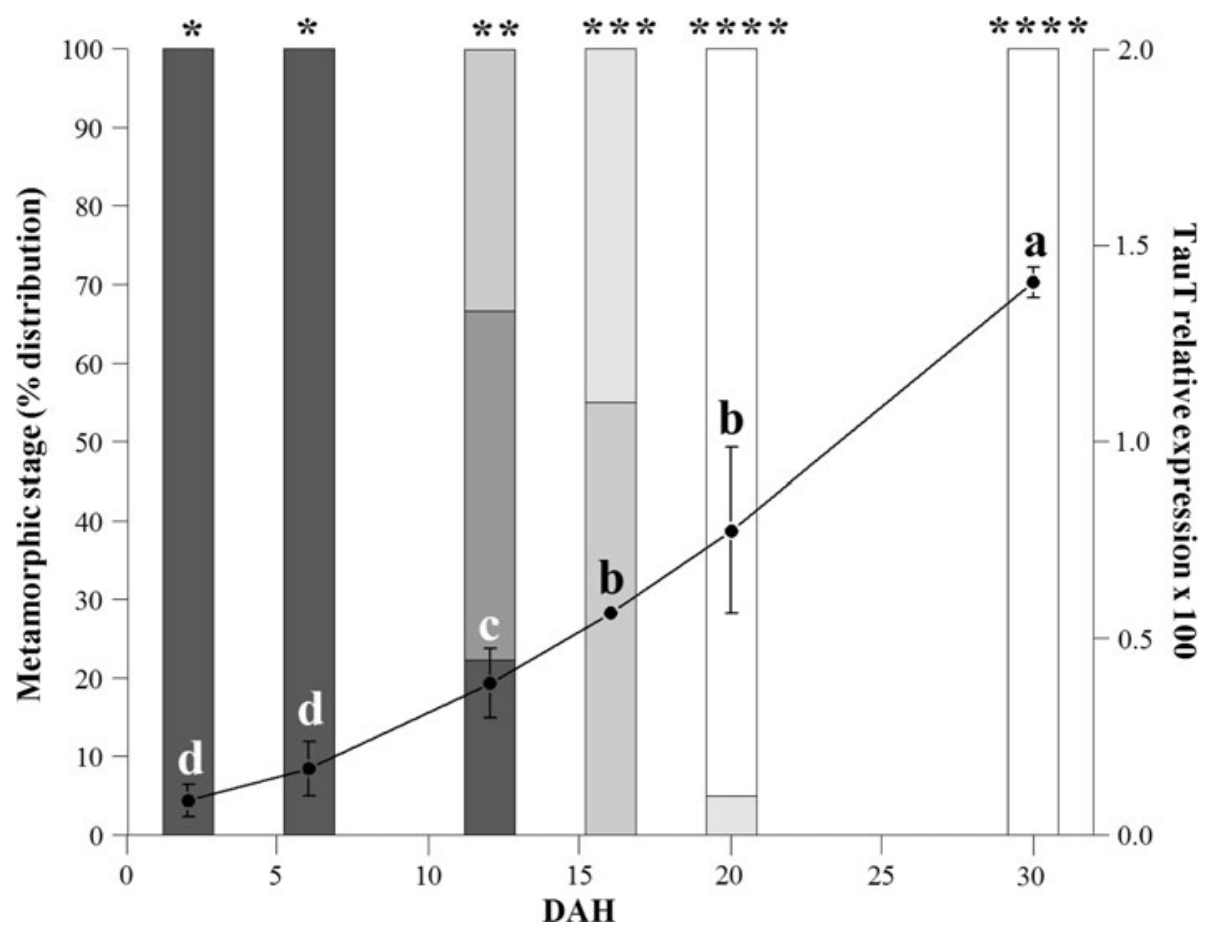

Fig. 2 Metamorphosis pattern and expression of taurine transporter (TauT) in S. senegalensis larvae reared under standard procedures. $\mathrm{DAH}$, days after hatching. Results for metamorphosis pattern are expressed as percentage of each metamorphic stage (0 dark bars; 1 dark grey bar; 2 light grey bar; 3 grey bar; 4 open bar) found at a certain age $(n=20)$. Results for expression of taurine transporter

dissected larvae, a similar trend was observed in all fractions (head, digestive tract and body), with TauT expression levels significantly increasing from 12 until $30 \mathrm{DAH}$ (Fig. 3). TauT expression decreased within compartments according to the following order: body $>$ head $>$ digestive tract.

In Senegalese sole juveniles, TauT was ubiquitously observed in all examined tissues (Fig. 4). The highest expression levels were found in brain, heart and eye. In the digestive tract, TauT was more expressed in hindgut and stomach. The expression of TauT was not significantly different among midgut or hindgut sections.

\section{Discussion}

This study describes the cloning of the full coding cDNA sequence for Senegalese sole TauT. The putative protein was formed by $625 \mathrm{AA}$, being easily identified by three signatures (sodium/chloride-dependent neurotransmitter transporter superfamily, neurotransmitter symporter family and taurine transporters) and the prediction of 12 transmembrane domains, a characteristic common in all TauT. Senegalese sole TauT exhibited a high similarity with other vertebrate TauT, sharing over $76 \%$ identity with mammals (filled circles) are shown as TauT copy:eEF1a1 copy $(n=3$ pooled samples). Results are given as mean \pm standard deviation. Different numbers of asterisks represents significant differences for the mean metamorphic stage at a certain age. Different letters represent significant differences for the expression of the taurine transporter throughout larval development

and more than $87 \%$ with other teleosts, which strongly suggests a high substrate specificity of transport. Accordingly, the phylogenetic tree constructed for vertebrate TauT grouped Senegalese sole among teleosts, indicating high evolutionary conservation of TauT in fish species.

Several studies have shown that few AA residues in S4 of TauT seem to be involved in the control of taurine transport (Han et al. 2006). Compared to other vertebrates, two noteworthy replacements are found for these AA in Senegalese sole, in positions 319 (R) and 322 (C). In the remaining vertebrates, position 319 is occupied by lysine (K), a positively charged AA that seems to be important for maintaining the loop structure and controlling the gating function of TauT by attracting the negatively charged aspartic acid (D) in position 325 (Han et al. 2006). The replacement of lysine by arginine (R319) in Senegalese sole may not affect this function, since arginine is also a positively charged AA and ion attraction with D325 will possibly be maintained. On the other hand, position 322 is occupied by a cysteine (C322) in fish, reptiles and birds, while in mammals a highly conserved serine is found in this position (S322). This replacement is likely to influence taurine uptake, since gating of TauT activity seems to be controlled by protein kinase C (PKC) phosphorylation of S322. For instance, Han et al. (1999) have shown that the 


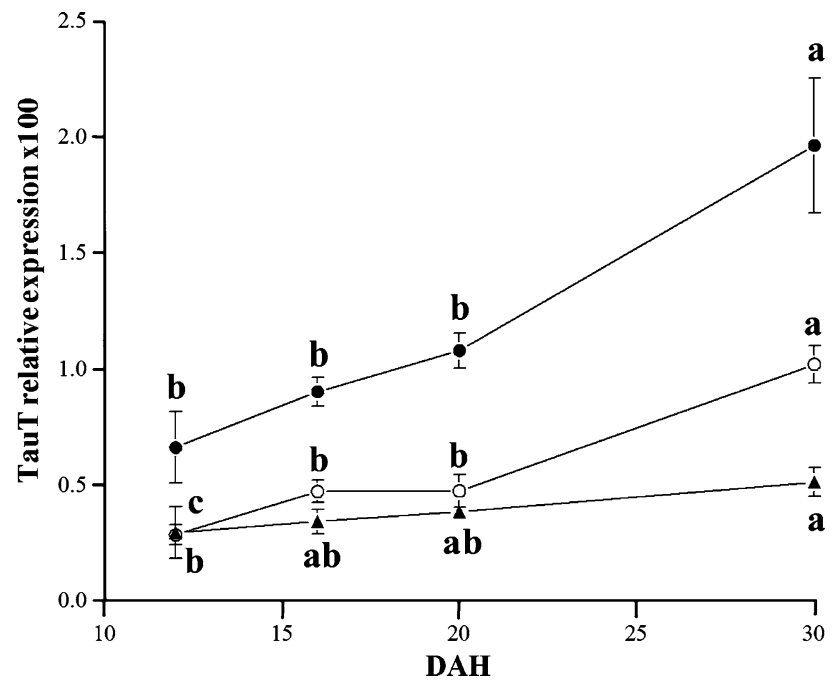

Fig. 3 Expression of taurine transporter (TauT) in dissected S. senegalensis larvae reared under standard procedures. DAH, days after hatching. Results for expression of taurine transporter in head (open circles), digestive tract (filled triangles) and body (filled circles) fractions are shown as TauT copy:eEF1al copy and given as mean \pm standard deviation ( $n=3$ pooled samples). Different letters within the same fraction represent significant differences throughout larval development

replacement of S322 by an alanine increased TauT activity by threefold in Xenopus laevis oocytes. Since alanine and cysteine phosphorylation by PKC cannot occur, these findings suggest that the replacement of S322 by C322 also result in a higher TauT activity. The biological explanation and consequences of this replacement on TauT activity in mammals compared with fish, reptiles and birds remain unknown and should be clarified.

In Senegalese sole larvae, TauT mRNA was found at the onset of exogenous feeding, and was found to significantly increase during the larval stage and during metamorphosis. A similar trend was observed in all fractions of dissected larvae (head, digestive tract and body), with TauT expression significantly increasing throughout metamorphosis. These results indicate that metamorphosis is an important developmental trigger to promote taurine transport in Senegalese sole larval tissues. These findings also show that although TauT mRNA can be found in Senegalese sole at the onset of exogenous feeding, it is during metamorphosis that the capacity to transport taurine increases. Nevertheless, it should be kept in mind that factors that influence taurine accumulation include ionic environment, electrochemical charge, post-translational and transcriptional factors (Han et al. 2006). However, Han et al. (2006), and Han and Chesney (1994) suggested that the long term adaptive response to diet is regulated at the mRNA level. Compared to the remaining fractions, TauT expression was very high in Senegalese sole body during the larval stage, indicating a high capacity to transport taurine in muscle during this period. In a developmental stage where growth potential is extremely high (Kamler 1992), this capacity may be important for larval growth, since taurine has been indicated to mediate the uptake of calcium in muscle sarcoplasmatic reticulum, playing a role on excitation-contraction mechanisms of muscle fibres (Huxtable 1992; De Luca et al. 2000), and to induce the uptake of AA into skeletal muscle cells (Huxtable et al. 1987). Since AA are the building blocks for growth (Carter and Houlihan 2001), a high capacity to transport taurine in muscle may be related to an increase of AA retention, leading to a high growth potential, as observed for Senegalese sole larvae reared under dietary taurine supplementation (Pinto et al. 2010). In addition, dietary taurine supplementation has also been reported to simultaneously increase taurine body levels and larval growth performance in other fish species, such as cod (Matsunari et al. 2005), red seabream (Chen et al. 2004) and Japanese flounder (Chen et al. 2005).
Fig. 4 Tissue expression of taurine transporter (TauT) in juvenile $S$. Senegalensis. $\mathrm{Br}$ brain, Ey eye, $G i$ gills, $H e$ heart, $H k$ headkidney, $S P$ spleen, $G b$ gallbladder, $L i$ liver, St stomach, $\mathrm{Mg}$ midgut, $\mathrm{Hg}$ hindgut, $\mathrm{Sec}$ sections from anterior to posterior. Results are shown as TauT copy:eEF1a1 copy and given as mean \pm standard deviation $(n=4)$. Different letters represent significant differences among fractions

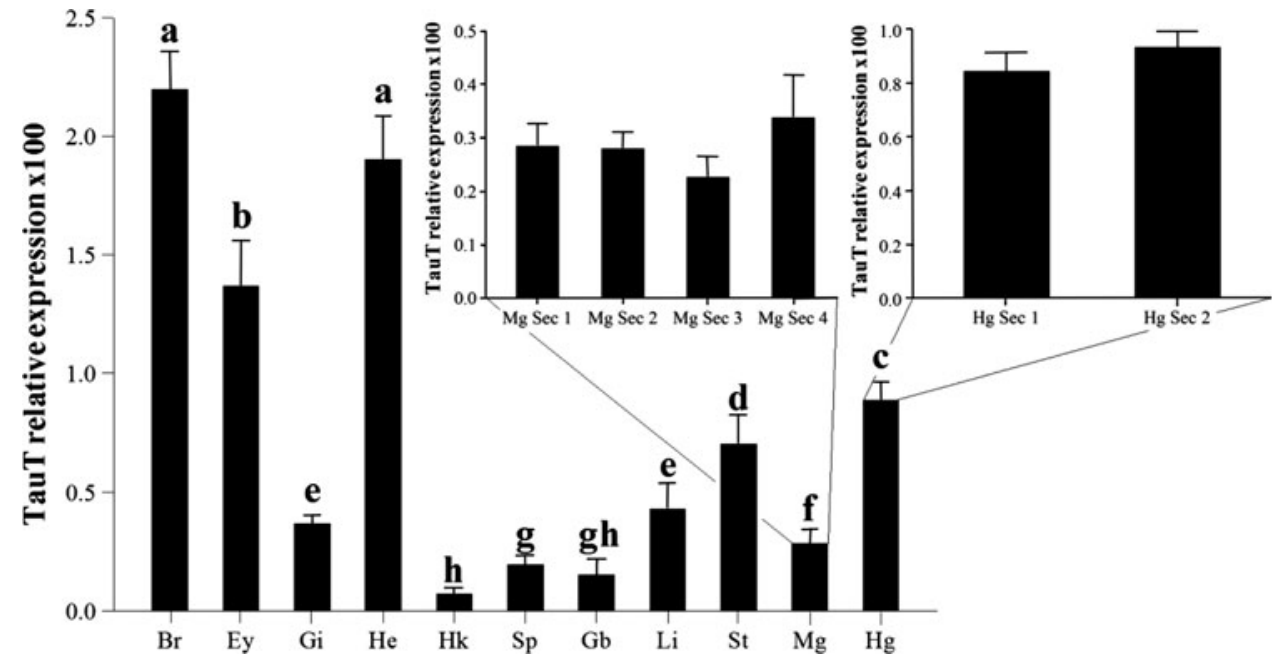


Contrary to what was observed for the body fraction, TauT expression in the digestive tract was lower in the remaining fractions throughout the experimental period. Although these results indicate that in comparison to the remaining fractions, Senegalese sole larvae may have a low ability to transport taurine in the digestive tract, the capacity to absorb dietary taurine at gut level seems to be already established, at least, from the onset of metamorphosis. The current data do not allow us to verify if TauT was expressed in the digestive tract earlier in the development, but it is observed that TauT expression in the digestive tract did not increase as much as in remaining fractions during larval development, suggesting that the capacity to absorb dietary taurine in the digestive tract is likely to be sufficiently high in the early larval stages.

The ubiquitous nature of TauT reported for juveniles of other fish species (Takeuchi et al. 2000, 2001; Zarate and Bradley 2007) was also found in Senegalese sole juveniles, since TauT was expressed in all examined tissues. Among these, TauT expression was particularly high in brain, heart and eye. Not surprisingly, these are organs where taurine can be found in high concentrations and has been suggested to play important roles (Huxtable 1992). For instance, taurine has been suggested to modulate neurotransmitter and synaptic activity, acting as a membrane stabiliser or playing a key role in cell volume regulation, a crucial factor for the normal function of the central nervous system (Huxtable 1989). In heart, taurine functions are mainly related to calcium modulation for cardiac muscle contraction, while in eye taurine has been indicated to prevent retinal degeneration by protecting photoreceptors, acting as a biological mirror behind the retina and having a shielding effect on rod outer segments on protection of high levels of light (Pasantes-Morales et al. 1981).

In the digestive tract of juveniles, TauT was more expressed in stomach and hindgut. Regarding stomach, this high expression of TauT indicates that dietary taurine is readily absorbed when the digestive process begins. It is not known when absorption of dietary taurine in the stomach region may start. Most studies conclude that altricial marine fish larvae do not have a functional stomach at the onset of first feeding (Rønnestad et al. 1999). However, in many fish the differentiation of stomach into a separate compartment with some short-term storage function appears to start prior to the onset of gastric acid and pepsin production as shown in Japanese flounder (Rønnestad et al. 2000). In Senegalese sole it has been suggested that the incipient stomach can already be observed at first feeding (Ribeiro et al. 1999), but the functional characterisation of this structure, including any taurine absorbing capacity, remains to be established. The high expression of TauT found in the hindgut of juvenile Senegalese sole also indicates that this area may be an important site of taurine absorption during the larval stage. The high expression of TauT found in the hindgut also suggests that taurine endogenously used for bile salt conjugation may be reabsorbed at the posterior end of the digestive tract. Therefore, these results suggest an enterohepatic recycling pathway for taurine in Senegalese sole, present at least from the juvenile stage. The enterohepatic recycling pathway of taurine is likely important for controlling taurine losses and maintaining taurine body pool in flatfish species. As observed in cats, the enterohepatic circulation of taurine can be disrupted by anaerobic bacteria in the digestive tract, leading to a deconjugation of taurine from bile salts (Ikeda et al. 1963). Taurine released during this process is reabsorbed or undergoes further bacterial degradation, being lost from the taurine body pool. These losses may be substantial (between 30 and $50 \%$ ) upon dietary factors that enhance bile secretion or increase taurine degradation by changes in gut flora (Cooke et al. 1988; Hickman et al. 1992). With this in mind, the results obtained in the current study suggest that future research should address understanding the mechanisms underlying the enterohepatic recycling pathway of taurine in flatfish species, as well as controlling losses from the taurine body pool resulting from dietary changes.

In conclusion, this study described the cloning and ontogenetic expression of TauT in the flatfish Senegalese sole. This transporter was highly similar to other vertebrate TauT, but changes in position 322 (S4) indicate that taurine transport may be different in mammals than in fish, reptiles or birds. Results also showed that Senegalese sole metamorphosis is an important developmental trigger to promote taurine transport, especially in larval muscle tissues. Moreover, results indicated that the larval capacity to absorb dietary taurine in the digestive tract seems to be established, at least from the onset of metamorphosis. In juveniles, taurine transport was especially high in brain, heart and eye, organs where taurine has been suggested to play important biological roles. Moreover, results from this study indicate that dietary taurine is quickly absorbed when the digestive process begins and taurine endogenously used for bile salt conjugation may be recycled at the posterior end of the digestive tract. Therefore, these results suggest an enterohepatic recycling pathway for taurine in Senegalese sole, at least in the juvenile stage, a process that may be important for maintenance of the taurine body levels in flatfish species.

Acknowledgments The authors would like to acknowledge A. Coelho \& Castro, Lda (Póvoa de Varzim, Portugal) for supplying Senegalese sole eggs and to Laura Ribeiro for suggestions on sampling procedures. W. Pinto is thankful to Anabela Bensimon-Brito for advice and support on molecular biology procedures and bioinformatics. W. Pinto is also grateful to the YGGDRASIL mobility program funded by the Research Council of Norway that granted him a 
research stay at the University of Bergen, Norway. W. Pinto and C. Aragão benefited from grants SFRH/BD/27889/2006 and SFRH/BPD/37197/2007 (FCT, Portugal), respectively. I. Rønnestad, A. -E. O. Jordal and A. S. Gomes acknowledge grants from European Community's Seventh Framework Programme (FP7/2007-2013) under grant agreement n 222719-LIFECYCLE.

Conflict of interest The authors declare no conflict of interest. The authors alone are responsible for the content and writing of this manuscript.

Open Access This article is distributed under the terms of the Creative Commons Attribution Noncommercial License which permits any noncommercial use, distribution, and reproduction in any medium, provided the original author(s) and source are credited.

\section{References}

Amberg JJ, Myr C, Kamisaka Y, Jordal AEO, Rust MB, Hardy RW, Koedijk R, Rønnestad I (2008) Expression of the oligopeptide transporter, PepT1, in larval Atlantic cod (Gadus morhua). Comp Biochem Phys B 150:177-182

Buddington RK, Diamond JM (1989) Ontogenetic development of intestinal nutrient transporters. Annu Rev Physiol 51:601-619

Bustin SA (2000) Absolute quantification of mRNA using real-time reverse transcription polymerase chain reaction assays. J Mol Endocrinol 25:169-193

Carter CG, Houlihan DF (2001) Protein synthesis. In: Wright PA, Anderson AJ (eds) Nitrogen Excretion. Academic Press, San Diego, pp 31-75

Chen JN, Takeuchi T, Takahashi T, Tomoda T, Koiso M, Kuwada H (2004) Effect of rotifers enriched with taurine on growth and survival activity of red sea bream Pagrus major larvae. Nippon Suisan Gakk 70:542-547

Chen JN, Takeuchi T, Takahashi T, Tomoda T, Koisi M, Kuwada H (2005) Effect of rotifers enriched with taurine on growth in larvae of Japanese flounder Paralichthys olivaceus. Nippon Suisan Gakk 71:342-347

Chow SC, Ching LY, Wong AMF, Wong CKC (2009) Cloning and regulation of expression of the $\mathrm{Na}^{+}-\mathrm{Cl}^{-}$taurine transporter in gill cells of freshwater Japanese eels. J Exp Biol 212:3205-3210

Conceição LEC, van der Meeren T, Verreth JAJ, Evjen MS, Houlihan DF, Fyhn HJ (1997) Amino acid metabolism and protein turnover in larval turbot (Scophthalmus maximus) fed natural zooplankton or Artemia. Mar Biol 129:255-265

Conceição LEC, Ribeiro L, Engrola S, Aragão C, Morais S, Lacuisse M, Soares F, Dinis MT (2007) Nutritional physiology during development of Senegalese sole (Solea senegalensis). Aquaculture 268:64-81

Cooke JA, Rogers QR, Morris JG (1988) Urinary and fecal excretion of taurine by cats fed commercial canned diets. Faseb J 2:A1617

De Luca A, Pierno S, Tricarico D, Desaphy JF, Liantonio A, Barbieri M, Camerino C, Montanari L, Camerino DC (2000) Taurine and skeletal muscle ion channels. Adv Exp Med Biol 483:45-56

Dinis MT, Ribeiro L, Soares F, Sarasquete C (1999) A review on the cultivation potential of Solea senegalensis in Spain and in Portugal. Aquaculture 176:27-38

Eck RV, Dayhoff MO (1966) Atlas of protein sequence and structure. Silver Springs, Maryland

Ennos R (2007) Statistical and data handling skills in biology. Pearson Prentice Hall, Harlow
Fernández-Díaz C, Yúfera M, Cañavate JP, Moyano FJ, Alarcon FJ, Díaz M (2001) Growth and physiological changes during metamorphosis of Senegal sole reared in the laboratory. J Fish Biol 58:1086-1097

Fleige S, Pfaffl MW (2006) RNA integrity and the effect on the realtime qRT-PCR performance. Mol Aspects Med 27:126-139

Goto T, Tiba K, Sakurada Y, Takagi S (2001) Determination of hepatic cysteinesulfinate decarboxylase activity in fish by means of OPA-prelabeling and reverse-phase high-performance liquid chromatographic separation. Fish Sci 67:553-555

Goto T, Matsumoto T, Murakami S, Takagi S, Hasumi F (2003) Conversion of cysteate into taurine in liver of fish. Fish Sci 69:216-218

Han X, Chesney RW (1994) Expression of taurine transporter and its regulation by diet in Xenopus laevis oocytes following injection of rat kidney cortex mRNA. Adv Exp Med Biol 359:121-130

Han X, Budreau AM, Chesney RW (1999) Ser-322 is a critical site for $\mathrm{PKC}$ regulation of the MDCK cell taurine transporter (pNCT). J Am Soc Nephrol 10:1874-1879

Han X, Patters AB, Jones DP, Zelikovic I, Chesney RW (2006) The taurine transporter: mechanisms of regulation. Acta Physiol 187:61-73

Hayes KC, Carey RE, Schmidt SY (1975) Retinal degeneration associated with taurine deficiency in cat. Science 188:949-951

Hickman MA, Bruss ML, Morris JG, Rogers QR (1992) Dietary protein source (soybean vs casein) and taurine status affect kinetics of the enterohepatic circulation of taurocholic acid in cats. J Nutr 122:1019-1028

Huxtable RJ (1989) Taurine in the central nervous-system and the mammalian actions of taurine. Prog Neurobiol 32:471-533

Huxtable RJ (1992) Physiological actions of taurine. Physiol Rev 72:101-163

Huxtable RJ, Franconi F, Giotti A (1987) The biology of taurine: methods and mechanisms. Plenum press, New York, p 404

Ikeda K, Tanaka S, Yamada H (1963) Bacterial degradation of taurine. J Biochem 54:312-316

Imsland AK, Foss A, Conceição LEC, Dinis MT, Delbare D, Schram E, Kamstra A, Rema P, White P (2003) A review of the culture potential of Solea solea and S. senegalensis. Rev Fish Biol Fish 13:379-407

Infante C, Matsuoka MP, Asensio E, Cañavate JP, Reith M, Manchado M (2008) Selection of housekeeping genes for gene expression studies in larvae from flatfish using real-time PCR. Bmc Mol Biol 9:28

Jhiang SM, Fithian L, Smanik P, Mcgill J, Tong Q, Mazzaferri EL (1993) Cloning of the human taurine transporter and characterization of taurine uptake in thyroid-cells. Febs Lett 318:139-144

Johns SJ (2010) TOPO2, Transmembrane protein display software. http://www.sacs.ucsf.edu/TOPO2/

Jones DP, Miller LA, Chesney RW (1995) The relative roles of external taurine concentration and medium osmolality in the regulation of taurine transport in Llc-Pk1 and Mdck Cells. Pediatr Res 37:227-232

Kamler E (1992) Early life history of fish: an energetic approach. Chapman and Hall, London

Kim SK, Takeuchi T, Yokoyama M, Murata Y (2003) Effect of dietary supplementation with taurine, beta-alanine and GABA on the growth of juvenile and fingerling Japanese flounder Paralichthys olivaceus. Fish Sci 69:242-248

Kim Sk, Takeuchi T, Yokoyam M, Murata Y, Kaneniwa M, Sakakura Y (2005) Effect of dietary taurine levels on growth and feeding behavior of juvenile Japanese flounder Paralichthys olivaceus. Aquaculture 250:765-774

Kim SK, Matsunari H, Takeuchi T, Yokoyama M, Furuita H, Murata Y, Goto T (2008) Comparison of taurine biosynthesis ability 
between juveniles of Japanese flounder and common carp. Amino Acids 35:161-168

Kozlowski DJ, Chen Z, Zhuang LN, Fei YJ, Navarre S, Ganapathy V (2008) Molecular characterization and expression pattern of taurine transporter in zebrafish during embryogenesis. Life Sci 82:1004-1011

Kubista M, Andrade JM, Bengtsson M, Forootan A, Jonák J, Lind K, Sindelka R, Sjöback R, Sjögreen B, Strömom L, Ståhlberg A, Zoric N (2006) The real-time polymerase chain reaction. Mol Aspects Med 27:95-125

Larkin MA, Blackshields G, Brown NP, Chenna R, McGettigan PA, McWilliam H, Valentin F, Wallace IM, Wilm A, Lopez R, Thompson JD, Gibson TJ, Higgins DG (2007) Clustal W and clustal X version 2.0. Bioinformatics 23:2947-2948

Liu QR, Lopezcorcuera B, Nelson H, Mandiyan S, Nelson N (1992) Cloning and expression of a cdna-encoding the transporter of taurine and beta-alanine in mouse-brain. Proc Natl Acad Sci USA 89:12145-12149

Matsunari H, Arai D, Koiso M, Kuwada H, Takahashi T, Takeuchi T (2005) Effect of feeding rotifers enriched with taurine on growth performance and body composition of pacific cod larvae Gadus macrocephalus. Aquac Sci 53:297-304

ÓFlaherty L, Stapleton PP, Redmond HP, Bouchier-Hayes DJ (1997) Intestinal taurine transport: a review. Eur J Clin Invest $27: 873-880$

Pasantes-Morales H, Ademe RM, Quesada O (1981) Protective effect of taurine on the light-induced disruption of isolated frog rod outer segments. J Neurosci Res 6:337-348

Pinto W, Figueira L, Ribeiro L, Yúfera M, Dinis MT, Aragão C (2010) Dietary taurine supplementation enhances metamorphosis and growth potential of Solea senegalensis larvae. Aquaculture 309:159-164

Ramamoorthy S, Leibach FH, Mahesh VB, Han H, Yangfeng T, Blakely RD, Ganapathy V (1994) Functional-characterization and chromosomal localization of a cloned taurine transporter from human placenta. Biochem J 300:893-900

Ribeiro L, Sarasquete C, Dinis MT (1999) Histological and histochemical development of the digestive system of Solea senegalensis (Kaup, 1858) larvae. Aquaculture 171:293-308

Rønnestad I, Fyhn HJ (1993) Metabolic aspects of free amino acids in developing marine fish eggs and larvae. Rev Fish Sci 1(3):239-259

Rønnestad I, Groot EP, Fyhn HJ (1993) Compartmental distribution of free amino acids and protein in developing yolk-sac larvae of Atlantic halibut (Hippoglossus hippoglossus). Mar Biol 116:349-354
Rønnestad I, Thorsen A, Finn RN (1999) Fish larval nutrition: a review of recent advances in the roles of amino acids. Aquaculture 177:201-216

Rønnestad I, Dominguez RP, Tanaka M (2000) Ontogeny of digestive tract functionality in Japanese flounder, Paralichthys olivaceus studied by in vivo microinjection: $\mathrm{pH}$ and assimilation of free amino acids. Fish Physiol Biochem 22:225-235

Rønnestad I, Kamisaka Y, Conceição LEC, Morais S, Tonheim SK (2007) Digestive physiology of marine fish larvae: hormonal control and processing capacity for proteins, peptides and amino acids. Aquaculture 268:82-97

Sturman JA (1988) Taurine in development. J Nutr 118:1169-1176

Sturman JA (1993) Taurine in development. Physiol Rev 73:119-147

Takeuchi T (2001) A review of feed development for early life stages of marine finfish in Japan. Aquaculture 200:203-222

Takeuchi K, Toyohara H, Sakaguchi M (2000) A hyperosmotic stressinduced mRNA of carp cell encodes $\mathrm{Na}^{+}$- and $\mathrm{Cl}^{-}$-dependent high affinity taurine transporter. Biochim Biophys Acta 1464:219-230

Takeuchi K, Toyohara H, Kinoshita M, Sakaguchi M (2001) Ubiquitous increase in taurine transporter mRNA in tissues of tilapia (Oreochromis mossambicus) during high-salinity adaptation. Fish Physiol Biochem 23:173-182

Tamura K, Dudley J, Nei M, Kumar S (2007) MEGA4: molecular evolutionary genetics analysis (MEGA) software version 4.0. Mol Biol Evol 24:1596-1599

Thompson JD, Gibson TJ, Plewniak F, Jeanmougin F, Higgins DG (1997) The CLUSTAL_X windows interface: flexible strategies for multiple sequence alignment aided by quality analysis tools. Nucleic Acids Res 25:4876-4882

Uchida S, Kwon HM, Yamauchi A, Preston AS, Marumo F, Handler JS (1992) Molecular cloning of the cNA for an Mdck Cell $\mathrm{Na}^{+}-$ dependent and $\mathrm{Cl}^{-}$-dependent taurine transporter that is regulated by hypertonicity. Proc Natl Acad Sci USA 89:8230-8234

van der Meeren T, Olsen RE, Hamre K, Fyhn HJ (2008) Biochemical composition of copepods for evaluation of feed quality in production of juvenile marine fish. Aquaculture 274:375-397

Verri T, Kottra G, Romano A, Tiso N, Peric M, Maffia M, Boll M, Argenton F, Daniel H, Storelli C (2003) Molecular and functional characterisation of the zebrafish (Danio rerio) PEPT1-type peptide transporter. Febs Lett 549:115-122

Yokoyama M, Takeuchi T, Park GS, Nakazoe J (2001) Hepatic cysteine sulphinate decarboxylase activity in fish. Aquac Res 32:216-220

Zarate JM, Bradley TM (2007) Molecular cloning and characterization of the taurine transporter of Atlantic salmon. Aquaculture 273:209-217 